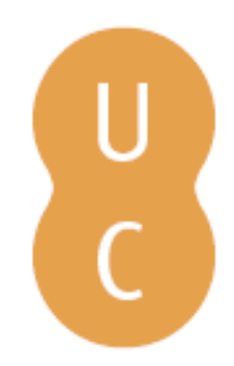

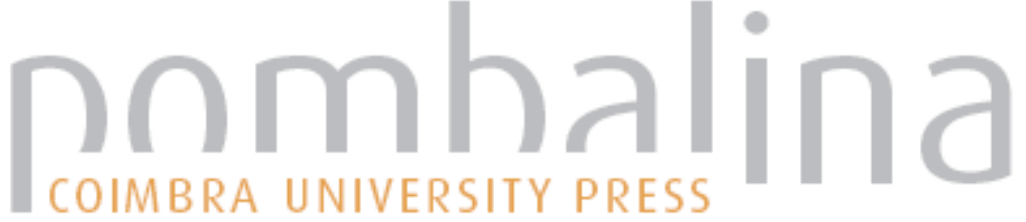

\section{A Biblioteca da Universidade e a República das Letras}

Autor(es): Silva, Vítor Aguiar

Publicado por: Imprensa da Universidade de Coimbra

URL

persistente: URI:http://hdl.handle.net/10316.2/36973

DOI: $\quad$ DOI:http://dx.doi.org/10.14195/978-989-26-1045-0_2

Accessed : $\quad$ 26-Apr-2023 09:02:26

A navegação consulta e descarregamento dos títulos inseridos nas Bibliotecas Digitais UC Digitalis, UC Pombalina e UC Impactum, pressupõem a aceitação plena e sem reservas dos Termos e Condições de Uso destas Bibliotecas Digitais, disponíveis em https://digitalis.uc.pt/pt-pt/termos.

Conforme exposto nos referidos Termos e Condições de Uso, o descarregamento de títulos de acesso restrito requer uma licença válida de autorização devendo o utilizador aceder ao(s) documento(s) a partir de um endereço de IP da instituição detentora da supramencionada licença.

Ao utilizador é apenas permitido o descarregamento para uso pessoal, pelo que o emprego do(s) título(s) descarregado(s) para outro fim, designadamente comercial, carece de autorização do respetivo autor ou editor da obra.

Na medida em que todas as obras da UC Digitalis se encontram protegidas pelo Código do Direito de Autor e Direitos Conexos e demais legislação aplicável, toda a cópia, parcial ou total, deste documento, nos casos em que é legalmente admitida, deverá conter ou fazer-se acompanhar por este aviso.

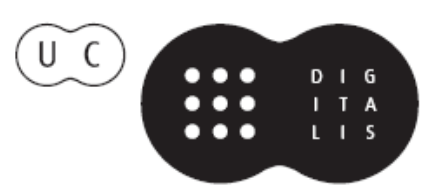



Tendo como pano de fundo as Comemorações dos seus 500 anos, a Biblioteca Geral da Universidade de Coimbra organizou um Congresso Internacional subordinado ao tema "A Biblioteca da Universidade: permanência e metamorfoses", que teve lugar nos dias 16, 17 e 18 de janeiro de 2014, no auditório da Reitoria da Universidade de Coimbra.

O objetivo maior desta reunião científica foi o de refletir sobre o presente e o futuro das bibliotecas que servem públicos universitários. Numa outra vertente, procurou chamar-se a atenção para a importância de que a Biblioteca se reveste, tendo em vista o progresso do conhecimento técnico e científico. Por último, o Congresso pretendeu instituir-se como oportunidade de reflexão prospetiva e como lugar de encontro entre as sensibilidades de todos os que trabalham profissionalmente com livros e com outros suportes de natureza bibliográfica.

Nesse sentido, foram apresentadas Conferências, Mesas Redondas e sessões de Testemunhos em torno de temas como o valor das bibliotecas universitárias, a biblioteca universitária em contexto; as mudanças e os desafios; a biblioteca universitária e a sociedade da informação e conhecimento; o impacto do acesso aberto na comunidade científica, e as bibliotecas digitais. 


\section{VÍTOR AGUIAR E SILVA}

Universidade do Minho

University of Minbo

A B I BLIOTECA DA UNIVERSIDADE

\section{E A REPÚBLICA DAS LETRAS}

ThE UNIVERSI LIBRARY AND THE REPUBLIC OF LETTERS

RESUMO: Origem e significado do termo e do conceito de respublica litteraria. Os ideais da respublica litteraria na cultura europeia desde o Renascimento até ao Iluminismo.

A república das letras e a modernidade iluminista.

A biblioteca como elemento fundamental das respublica litteraria e da república das letras, sob o signo da unidade do conhecimento das letras, das artes e das ciências.

A dinâmica da progressiva autonomização dos campos culturais, o "divórcio» entre as humanidades e as ciências e a irreversível especialização do conhecimento no âmbito das ciências exactas e da natureza e no âmbito das ciências humanas e sociais. As incidências destas modificações na Universidade europeia ao longo dos séculos XIX e XX. A conversão da Universidade numa multidiversidade de territórios insulares do conhecimento, do ensino e da investigação. A criação de bibliotecas especializadas nas Faculdades, nos Departamentos, nos Centros e nos Programas das Universidades.

A interdisciplinaridade e a transdisciplinaridade como orientações epistemológicas e metodológicas que, nas últimas décadas, têm instituído novos modos de diálogo e de interacção entre os saberes disciplinares. O papel insubstituível das bibliotecas neste diálogo e nesta interacção.

A Biblioteca da Universidade como locus privilegiado da cartografia arquipelágica da Universidade contemporânea, como espaço de estudo interdisciplinar e transdisciplinar e como recuperação institucional, na modernidade do século XXI, das grandes linhas de força da república das letras.

ABSTRACT: Origins and meaning of the term and concept respublica litteraria. Ideas of the respublica litteraria in European culture, from the Renaissance to the Enlightenment.

The Republic of Letters and Enlightenment modernity.

The library as an essential component of the respublica litteraria and the Republic of Letters, reflecting unity of knowledge within the humanities, arts and sciences.

The dynamics of the gradual separation of cultural fields, the "divorce» between the humanities and sciences, and the irreversible specialisation of knowledge within 
the exact and natural sciences and the human and social sciences. Incidences of these changes within the European university in the $19^{\text {th }}$ and $20^{\text {th }}$ centuries. The transformation of the University into a multidiversity of islands of knowledge, teaching and research. The creation of specialist libraries within university faculties, departments, research centres and teaching programmes.

Interdisciplinarity and transdisciplinarity as epistemological and methodological principles which, in recent decades, have established new forms of dialogue and interaction between disciplines. The irreplaceable role of libraries in this dialogue and interaction.

The university library as the favoured locus for the "island" cartography of the modern university, a space for interdisciplinary and transdisciplinary study and for the institutional regeneration of the main principles of the Republic of Letters within $21^{\text {st }}$ century modernity.

Agradeço ao Senhor Director da Biblioteca Geral da Universidade de Coimbra, Doutor José Augusto Cardoso Bernardes, o convite que teve a generosidade de me dirigir para pronunciar a conferência de abertura deste Congresso.

Comemorar cinco séculos da história de uma instituição como a Biblioteca Geral, que no início do século XVI era uma modesta "livraria» e que hoje é a mais importante biblioteca universitária do mundo lusófono, é motivo de justificados júbilo e orgulho para todos os universitários, sobretudo quando, como é o meu caso, encontraram nesta Casa muitos dos instrumentos de trabalho com os quais construíram o seu curriculum académico.

Há cinquenta e seis anos, no início do segundo período do ano escolar de 1957-58, entrei pela primeira vez na vasta e sombria sala de leitura da antiga Biblioteca, instalada no Pátio da Universidade. Fui consultar a obra de um autor alemão, em tradução espanhola, sobre filosofia da linguagem, por indicação do Doutor Manuel de Paiva Boléo. Depois desse baptismo, tornei-me leitor assíduo da velha e a seguir da nova Biblioteca.

A minha tese de doutoramento ficou a dever muito aos fundos bibliográficos antigos que a Biblioteca Geral possui e muito em especial aos manuscritos da secção de "Reservados». Foi numa sala desta secção que tive a sorte de encontrar, entre papéis vários do espólio de Carolina Michaëlis de Vasconcelos, a cópia manuscrita da quase totalidade das 
composições do Cancioneiro Fernandes Tomás, realizada a pedido da sábia filóloga. Como o original do Cancioneiro era sonegado persistentemente aos investigadores pelo director da instituição pública que o detinha - o Museu Nacional de Arqueologia e Etnografia -, fiquei a dever a este achado que a minha tese de doutoramento não sofresse de múltiplas lacunas.

Relembro com saudade e gratidão os Directores desta Biblioteca que conheci, que me honraram com a sua amizade e que a morte colheu no seu regaço: o Doutor Manuel Lopes de Almeida, o Doutor Guilherme Braga da Cruz, o Doutor Luís Albuquerque e o Doutor Aníbal Pinto de Castro, meu fraterno amigo.

Quero também prestar homenagem ao Doutor Carlos Fiolhais, um Director cujo perfil académico se enquadra admiravelmente na «República das Letras" de que irei falar, e ao Doutor José Cardoso Bernardes, actual Director, a cuja inteligência e abertura de espírito e a cujo sentido de equilíbrio intelectual e institucional a Biblioteca Geral da Universidade de Coimbra - e com ela todos nós - muito ficará a dever.

O termo e o conceito de respublica litteraria (ou literaria) encontram-se documentados pela primeira vez numa epístola latina, datada de 6 de Julho de 1417, que o humanista veneziano Francesco Barbaro dirigiu a outro humanista, Poggio Bracciolini (1380-1459), o qual tinha acabado de descobrir, no mosteiro suíço de Saint Gall, importantes manuscritos de autores latinos, entre os quais os da Institutio Oratoria de Quintiliano, o das Argonautica de Valerius Flaccus e os comentários de Quintus Asconii Pediani a oito orações de Cícero ${ }^{1}$. Poggio Bracciolini, numa epístola endereçada ao humanista Guarino Veronese (c. 1370-1460) na qual dá notícia de tão valioso achado, informa que «estes livros não estavam na

1 Veja-se Fumaroli, Marc - «La République des Lettres». Diogène. N. ${ }^{\circ} 143$ (1988), p. 137. Marc Fumaroli tem consagrado à respublica litteraria estudos fundamentais, agora coligidos na obra La República de las Letras. Trad de J.R. Monreal. Barcelona: Alcantilado, 2013. Sobre o conceito de respublica litteraria, vide duas obras relevantes: GOODMAN, Dena - The Republic of Letters. A cultural history of french Enlightenment. Ithaca-London: Cornell University Press, 1994; BOTS, Hans e WAQUET, Françoise - La République des Lettres. Paris: Belin, 1997. 
biblioteca, como a sua dignidade requeria, mas num horroroso e escuro cárcere, onde não se prenderiam sequer os condenados à morte» ${ }^{2}$.

A fórmula respublica litteraria, provavelmente inspirada na expressão respublica christiana, utilizada por Santo Agostinho na Cidade de Deus (II, 21; XIX, 21-26), designa uma comunidade ideal, não institucionalizada social e juridicamente, mas ao mesmo tempo real, formada por doctissimi homines ubicumque, congregados pelos laços das letras, do estudo e do saber (necessitudo litterarum), e empenhados na realização de trabalhos úteis ao bem comum (pro communi utilitate labores), como realça Francesco Barbaro na referida epístola. Na Itália do norte e do centro, de Roma a Veneza, de Pádua e Florença a Milão, constituiu-se, ao longo do século $\mathrm{XV}$, graças à renovatio litterarum, que se identificava com a renovatio antiquitatis, e graças aos studia humanitatis, que consubstanciavam o ideal da translatio studii, um poder espiritual novo, partícipe da esfera religiosa e da esfera secular e do qual eram agentes tanto clerici como laici. Segundo as palavras autorizadas de Marc Fumaroli, Petrarca deve ser justamente reconhecido como o fundador da respublica litteraria, desse novo poder espiritual que o genial poeta, pensador, tratadista e epistológrafo, fez surgir nos «interstícios entre a Igreja e os Estados»3.

$\mathrm{O}$ ideal da respublica litteraria (ou respublica litterarum) ganhou vigor e irradiação ao longo dos séculos XVI e XVII, salvaguardando, numa Europa dilacerada com frequência por guerras políticas e por conflitos religiosos, o poder das ideias, cultivando a liberdade e a tolerância espirituais, acreditando na capacidade civilizadora das letras humanas e da razão crítica. Durante a primeira metade do século XVI, Erasmo foi o príncipe desta eruditorum societas, que se tornou progressivamente, não obstante as limitações censórias impostas pelos poderes religiosos e políticos, uma comunidade cosmopolita que congregou homens e também mulheres de diversas nações, diversas crenças religiosas e diversas

2 A carta de Poggio Bracciolini está publicada em latim e em tradução italiana em QUONDAM, Amedeo (a cura di) - Rinascimento e Classicismo. Materiali per l'analisi del sistema culturale di Antico regime. Roma: Bulzoni Editore, 1999, p. 48-53.

3 Fumaroli, Marc - Rome et Paris - Capitales de la République européenne des Lettres. Hamburg: LIT Verlag, 1999, p. 27. 
condições sociais. Erasmo, com a irradiação da sua obra multiforme de pensador, de moralista, de filólogo e de pedagogo, com as suas relações de amizade com relevantes figuras da cultura europeia, muitas das quais conheceu pessoalmente durante as suas viagens pela França, pela Itália, pela Inglaterra, pelos Países Baixos e pela Suíça, alargou a respublica litteraria, originariamente confinada à Itália dos humanistas, até aos limites da respublica christiana.

Os impressores e os mercadores de livros, ao produzirem e difundirem, em toda a Europa, uma grande variedade de textos através do livro impresso, recorrendo muitas vezes à tradução, contribuíram de modo decisivo para a expansão da respublica litteraria. Aldo Manuzio (1449-1515), o insigne impressor e filólogo, amigo de humanistas como Poliziano, Pico della Mirandola e Erasmo, converteu Veneza, desde a última década do século XV, no mais importante centro de produção e de comércio do livro na Europa e tornou-se, com as epístolas prefaciais das suas edições, endereçadas aos studiosi bonarum litterarum, aos amantissimi bonarum litterarum, «um verdadeiro porta-voz de uma República das Letras em expansão na Europa inteira", como sublinha Marc Fumaroli. O latim, em particular o latim ciceroniano, era a língua que identificava e prestigiava os membros dessa sodalitas litterarum. A correspondência epistolar, tornada mais célere e mais segura com a criação do serviço postal, facilitou e fortaleceu o intercâmbio de ideias e de projectos entre os doctissimi homines ubicumque. Desde os primeiros anos do século $\mathrm{XVII}$, os jornais e as gazetas tornaram-se um instrumento privilegiado de comunicação entre os membros da eruditorum societas e o público leitor. A criação e o desenvolvimento das Academias, mesmo quando estas eram tuteladas pelo poder político, como aconteceu com a Academia Francesa, contribuíram para consolidar institucionalmente a respublica litteraria.

A diáspora de muitos intelectuais protestantes franceses, obrigados a procurar refúgio no exílio, antes e sobretudo depois da revogação do édito de Nantes (1685), fez com que os Países Baixos, que já no século XVI tinham sido o lugar de expatriação de muitos judeus hispânicos, se convertessem no principal espaço geográfico e político de acolhimento dos homens franceses de letras exilados. Um desses intelectuais, Pierre 
Bayle (1647-1706), fundou em Roterdão, em 1684, o jornal intitulado Nouvelles de la République des Lettres que, conjuntamente com a Gazette de Leyde e a Gazette d'Amsterdam, contribuiu para que a respublica litteraria humanística passasse a ser denominada com frequência République des Lettres, tendo no francês a sua língua hegemónica.

O Iluminismo foi o herdeiro da respublica litteraria humanista e da république des lettres de Pierre Bayle, desenvolvendo e difundindo, através de formas novas de sociabilidade e de comunicação, o combate das «Luzes» contra a ignorância, do cosmopolitismo contra o provincialismo, do racionalismo crítico contra o dogmatismo e o fanatismo, da liberdade política e religiosa contra a censura e a opressão. Nas palavras memoráveis de Pierre Bayle, "[c]'est la liberté qui règne dans la République des Lettres. Cette République est un état extrêmement libre. On n’y reconnait que l'empire de la vérité et de la raison" ${ }^{4}$. Os membros desta República ideal reivindicam inteira liberdade de espírito, reconhecem tão-só a autoridade da razão e da experiência, exaltam a sua pertença ao "mundo literário» e ao "orbe literário", que os isenta dos particularismos e constrangimentos impostos pelas nações: "Entre os sábios não há nações», escrevera já D. Francisco Manuel de Melo no Hospital das Letras, "donde já disse um dos gregos que era cidadão do mundo todo".

A res litteraria que congregava os "eruditi homines" da respublica litteraria, "les savants» da République des Lettres, os «sábios» do orbe literário, não era a literatura tal como esta veio a ser progressivamente concebida, escrita e lida, desde a segunda metade do século XVIII até aos nossos dias, isto é, como a arte que utiliza a linguagem verbal para produzir textos de natureza estética. A república das letras congregou no mesmo ideal de conhecimento e de cultura os significados que, durante séculos, nas diferentes línguas europeias, possuíram as palavras literatura, literário e letras. Assim, a república literária compreende as várias artes, da poesia à pintura e à música, a história, a eloquência, a teologia, o direito, a matemática, a astronomia, a medicina, a física, etc., configu-

4 GOODMAN, Dena - The Republic of Letters. A cultural history of french Enlightenment, p. 12 . 
rando um ideal de enciclopédia ou polimatia anterior ao "divórcio" entre as ciências e as humanidades - um «divórcio que se foi desenhando e aprofundando no decurso do século XVIII e de que os Principi di scienza nuova de Giambattista Vico, cuja edição definitiva data de 1744, foram a primeira formulação ou a primeira revelação, para o melhor ou para o pior, segundo as palavras de Isaiah Berlin ${ }^{5}$.

Entre os numerosos testemunhos do significado plural, polimático e pluridisciplinar, da res litteraria nos séculos XVII e XVIII, mencionarei tão-só a República literaria de Diego de Saavedra Fajardo (1584-1648) e as Notícias literárias de Portugal de José Anastácio da Cunha (1744-1787).

A República literaria de Saavedra Fajardo, que foi um importante e cosmopolita diplomata ao serviço da monarquia espanhola, é uma extraordinária sátira menipeia - o modelo greco-latino deste género literário fora renovado por Justo Lípsio com a obra Satyra Menippaea. Somnium (1581) -, cuja primeira redacção datará da segunda década do século XVII. Em vez das laudes litterarum, tão frequentes na tradição humanística, Saavedra Fajardo escreve uma jocosa vituperatio litterarum em que a res litteraria é representada pela poesia, pela pintura, pela escultura, pelas artes liberais, pela eloquência, pela história, pela filosofia moral e política, pelo direito, pela medicina, etc., povoando cada uma destas áreas as mais relevantes e célebres figuras, desde a antiguidade clássica até à modernidade de Seiscentos.

José Anastácio da Cunha, que foi lente de Geometria na Universidade de Coimbra, de 1773 até 1778, ano em que foi encarcerado e processado pela Inquisição, redigiu em 1780, em língua francesa, um breve memorial intitulado Notícias literárias de Portugal sobre a "república das letras" no nosso país - memorial que se conserva manuscrito no Arquivo Nacional do Rio de Janeiro e que foi editado, em língua francesa e com a tradução em língua portuguesa, por Joel Serrão, em 1966 (Lisboa, Seara Nova). "O lente penitenciado», para usar a expressão de Aquilino Ribeiro, exalta reiteradamente como glória maior da "república das letras» Camões, "O

5 BERLIN, Isaiah - El estudio adecuado de la humanidad. Trad. de Francisco Gonzáles Aramburo et alii. Madrid-México: Turner e Fondo de Cultura Económica, 2009, p. 261. 
nosso poeta, o imortal Camões, [que] merece sem dúvida ser arrolado entre os maiores poetas do mundo, antigos e modernos", menciona os dois poetastros [sic] António Ferreira e Sá de Miranda, cujos versos rudes fazem «estarrincar os dentes» [grincer les dents»], refere-se de modo vago ao labor poético dos reis D. Dinis e D. Pedro I, mofa dos homens de letras denominados no século XVII "Discretos e Cultos». Não restringe a sua informação e os seus juízos, porém, à esfera da poesia. Menciona um bom geómetra e astrónomo como Pedro Nunes, um notável geógrafo e cosmógrafo como D. João de Castro, alguns latinistas e eruditos de mérito, como André de Resende e Jerónimo Osório, uns tantos historiadores e pesquisadores de antigualhas, matemáticos como Martim Afonso de Sousa, que se notabilizou sobretudo como político e como militar, médicos como Abraão Zacuto e Amato Lusitano, alguns pintores de certo mérito. Lamenta, porém, que em Portugal não tenha existido um grande pintor, nem um escultor e um arquitecto comparáveis aos artistas medianos da Itália e da França. Sublinha o mérito minguadíssimo de alguns doutores em Direito e não faz sequer uma referência a teólogos. Em suma, segundo José Anastácio da Cunha, a "república das letras» compreende a poesia, as artes plásticas, a história, a matemática, a astronomia, a geometria, a geografia, a medicina, o direito e a ciência da agricultura.

O significado amplo e complexo do termo «literário» avulta sobremaneira no passo das Notícias em que é referida a criação por D. Dinis da Universidade portuguesa, passo que citarei na língua francesa original: «Nous lui devons l'université; c'est un ouvrage littéraire qui doit nous consoler de la perte des autres» [das obras escritas por D.Dinis]. Traduzir "ouvrage littéraire", neste contexto, por "obra literária" é trair o pensamento do autor, que concebe a Universidade como a instituição na qual são professados os saberes científicos e as artes que perfazem, no seu conjunto e na sua inter-relação, um domínio fundamental da «república das letras".

A modernidade iluminista revelou um claro e vigoroso entendimento de que nas Universidades e, mais alargadamente, em toda a "República das Letras", era necessário instituir e praticar a cooperação adequada entre os vários saberes constitutivos do orbis litterarum, de modo que 
a Teologia, o Direito e a Medicina consolidassem os seus fundamentos e progredissem nos seus campos específicos, beneficiando do estudo e do conhecimento de outras disciplinas que configuram a história literária geral de baconiana genealogia. O Compêndio histórico do estado da Universidade de Coimbra (1771) advoga reiteradamente esta orientação interdisciplinar, invocando a autoridade de Cícero e de Quintiliano para estatuir que há "entre as Sciencias, como entre as Virtudes, hum certo nexo, e sociedade: Com que todas mutuamente se ajudam, e nenhuma póde separar-se da outra, sem arruinar-se, ou fazer-se disforme o seu edifício» (parte II, capítulo III).

Este modelo pluridisciplinar e interdisciplinar da criação e da organização do conhecimento, cuja genealogia remonta imediatamente aos ideais de polymathia do Humanismo e da pansofia do humanista e pedagogo checo Jan Comenius (1590-1670) e que foi defendido pelas vozes mais relevantes do Iluminismo europeu, foi representado pela metáfora da árvore do conhecimento, com um tronco comum e com múltiplos ramos e sub-ramos, e foi também designado, desde o século XVII, com o termo «sistema» e até pela expressão, de impressionante modernidade semiológica, de «sistema de sistemas» ${ }^{6}$. Francisco Dias Gomes (1745-1795), sofrível, senão medíocre, poeta neoclássico, mas inteligente e bem informado crítico literário, no escólio que elaborou sobre a sua Elegia I, intitulada "Às Musas", escreveu que o seu poema discorre "por aquellas faculdades que fazem maior vulto no systema litterario, quaes são a Escultura, a Pintura, a Mathematica, a Historia, a Eloquencia, a Musica e a Poesia ${ }^{7}$.

As bibliotecas foram um elemento fundamental na actividade da militia litterarum, sobretudo após a difusão, em toda a Europa, do livro impresso, proporcionando aos leitores o conhecimento dos textos relevantes para as diversas artes e as diversas ciências integradas na respublica litteraria. Erasmo, num aditamento ao seu comentário ao adágio Herculei labores, exalta o papel da biblioteca de Aldo Manuzio na propagatio litterarum,

6 BURKe, Peter - Historia social del conocimiento. Trad. de Isidro Arias. Barcelona: Paidós, 2002, p.119.

7 Gomes, Francisco Dias - Obras poeticas. Lisboa: Typographia da Acad. R. das Sciencias, 1799, pp.12-13. 
pois as edições aldinas eram uma espécie de fonte que alimentava as boas bibliotecas por toda a terra:

"Eu via claramente que esse esforço não era obra de um só homem, nem de uma única biblioteca, nem de poucos anos, e levámo-la a termo sozinhos, com as nossas armas, por assim dizer, em menos de um ano e meio, e com a ajuda, na aparência, de uma única biblioteca. Mas era a biblioteca de Aldo, riquíssima em si mesma e mais bem provida do que nenhuma outra de bons livros, em especial gregos: de tal modo que dela, como uma fonte, nascem e prosperam por toda a terra as boas bibliotecas" ${ }^{8}$

Com efeito, confirmando as palavras de Erasmo, multiplicaram-se por toda a Europa, nos séculos XVI e XVII, as grandes bibliotecas públicas e privadas. As Universidades, que desde os seus primórdios tiveram no livro manuscrito um instrumento fundamental na transmissão do conhecimento - "Sem exemplares", declaram os estatutos da Universidade de Pádua em 1264, "não haveria Universidade» - ${ }^{9}$, aumentaram e enriqueceram substancialmente o seu património bibliográfico graças ao livro impresso, como aconteceu com a Sorbonne e com a Universidade de Oxford, que em 1602 refundou a sua biblioteca, criada em 1334, com a famosa Bodleyan Library.

Um exemplo elucidativo de criação e de organização de uma biblioteca geral universitária que correspondia aos ideais de cultura e de estudo da república literária é o da Universidade de Leiden, uma Universidade protestante criada em 1575 . Uma gravura datada de 1610 proporciona uma visão muito bela do espaço luminoso da biblioteca, assinalando nos dois renques de onze estantes cada um, abertas à consulta dos leitores, a ordo disciplinarum segundo a qual se distribuíam as espécies bibliográficas: no renque da direita, sucedem-se as disciplinas de história, de

\footnotetext{
8 FUMAROLI, Marc - «La République des Lettres», p. 149.

9 LE GOFF, Jacques - Alle origini del lavoro intellettuale in Italia. I problemi del rapporto fra la letteratura, l'università e le professioni. In Letteratura italiana. Volume primo. Il letterato e le istituzioni. Torino: Einaudi, 1982, p. 652, n. 8. O exemplar era um manuscrito constituído pela junção de vários cadernos de quatro folhas.
} 
medicina e de direito; no renque da esquerda, alinham-se as disciplinas de matemática, de filosofia, de gramática e filologia e de teologia.

A expansão e a diversificação dos saberes, das artes e das ciências que formavam a república das letras - processo iniciado já no século XVII -, intensificaram-se ao longo do século XVIII: ganharam relevância ciências como a física, a química, a biologia e a botânica; criaram-se escolas superiores de tecnologia; autonomizou-se o domínio da estética e constituiu-se o moderno conceito de literatura; ocorreu o já referido "divórcio" entre as humanidades e as ciências, que representou a ruptura da unidade secular, complexa e difícil, da república das letras, no quadro de uma progressiva e irreversível especialização do conhecimento, tanto no âmbito das ciências exactas e naturais como no âmbito das ciências humanas e sociais.

Estas transformações no conhecimento e nas respectivas disciplinas originaram profundas mudanças institucionais, organizativas e funcionais, nas Universidades: foram criadas novas Faculdades, novos Departamentos, novos Institutos e novas Cátedras, que contemplaram novos domínios do saber, do ensino e da investigação. Em tempos mais recentes, foram criadas novas unidades - ou microunidades - orgânicas como os Centros e os Programas.

As Faculdades, os Departamentos, os Institutos, os Centros e os Programas constituíram em geral bibliotecas próprias, cuja especialização corresponde à especialização crescente dos saberes aí professados. Por isso mesmo, diversas Universidades prescindiram da criação de Bibliotecas gerais ou reduziram-nas às funções de custódia de valioso património bibliográfico antigo. Múltiplos factores interferem nestas opções, desde a configuração descontínua ou multipolar dos espaços universitários até à gestão de verbas próprias geradas por bolsas, projectos de investigação, patentes, etc. Não nos esqueçamos de que o princípio da autonomia que a Universidade em geral reivindicou perante o poder, religioso ou político, se manifesta isomorficamente, ad intra, em todo o corpo universitário. Como observou Norbert Elias, num estudo que dedicou aos estabelecimentos científicos, as metáforas territoriais que, desde o século XIX, têm sido frequentemente utilizadas para fazer referência aos diversos saberes 
e ensinos disciplinares - "campo", "terreno", "domínio" - transportam consigo conotações defluentes da esfera da soberania da nação-estado, tais como a existência de fronteiras bem delimitadas, a inviolabilidade do território, a hostilidade em relação a migrantes e a franco-atiradores ${ }^{10}$.

A fim de evitar que os territórios disciplinares da Universitas fechem as suas fronteiras uns aos outros ou, para utilizar uma metáfora geográfica e cartográfica, a fim de evitar que a Universitas se fragmente numa diversitas arquipelágica de ilhas do conhecimento, do ensino, da investigação e da poiesis, torna-se necessário conceber e pôr em prática políticas que propiciem e incrementem o diálogo e a interacção entre os saberes disciplinares dentro da mesma Faculdade e do mesmo Departamento e entre Faculdades e Departamentos diferentes. A interdisciplinaridade e a transdisciplinaridade não bloqueiam nem impedem a especialização disciplinar, antes a densificam e complexificam. A interdisciplina de hoje será muitas vezes a disciplina de amanhã.

$\mathrm{Na}$ cartografia arquipelágica em que se encontra representada grande parte da Universidade contemporânea, a Biblioteca da Universidade poderá constituir, em meu entender, uma espécie de "Ilha Afortunada» como locus institucional privilegiado do diálogo, da reflexão e da prática interdisciplinares que recusam a fragmentação crescente e, no limite, o insulamento radical dos saberes. A Biblioteca da Universidade, sem lesar as bibliotecas das Faculdades, dos Departamentos, dos Institutos, dos Centros e dos Programas, proporcionará a professores e alunos os instrumentos de informação, de estudo, de reflexão e de trabalho intelectual que possibilitem recuperar, no contexto cultural e científico do século XXI, grandes linhas de força da república das letras humanística e iluminista.

Ilusão? Utopia? Sou dos que entendem a utopia como iluminação antecipadora de caminhos futuros e como desvelamento e fermentação do "princípio-esperança", perante a facticidade reificada da história. Aos

10 ELIAS, Norbert - «Scientific Establishments». In ELIAS, Norbert, MARTINS, Herminio e WHITLEY, Richard (eds.) - Scientific Establishments and Hierarchies. Dordrecht: Reidel, 1982, p.3-69. 
cépticos, recomendo a leitura do Report of the Task Force on General Education elaborado por um qualificado grupo de trabalho da Universidade de Harvard, constituído por professores das áreas das ciências exactas e naturais e das ciências humanas e sociais, que fundamentou o novo curriculum de educação geral em vigor desde 2007 no College daquela Universidade. Os ideais e os objectivos da educação liberal advogados no referido relatório exprimem e consubstanciam, na modernidade da primeira década do século XXI, muitos dos ideais da república das letras:

"General education courses are distinguished by their emphasis on breadth, on context, on connectedness, and on the relation between the material students are studying and things they will be doing for the rest of their lives: interpreting cultural artifacts, participating in political processes, coping with the ramifications of technological developments, interacting with people from diverse backgrounds, assessing the various scientific claims that are made in public discourse, and facing ethical dilemmas in their personal and professional lives. [...] Liberal education is vital because professional schools do not teach these things, employers do not teach them, and even most academic graduate programs do not teach them. Those institutions deliberalize students: they train them to think as professionals. A preparation in the liberal arts and sciences is crucial to the ability to think and act critically and reflectively outside the channels of a career or profession".

Os sistemas de ensino superior com orçamento relativamente pobre ou perigosamente empobrecido, ano após ano, como é o caso do sistema português, são solicitados ou são compelidos pelos decisores políticos, pelos empregadores e pelos agentes económicos em geral, a profissionalizarem rapidamente os seus alunos, que depois serão mais facilmente proletarizáveis sob todos os pontos de vista. Um curriculum de educação geral e de educação liberal como o do College da Universidade de Harvard seria em Portugal considerado como um luxo-desperdício. A riqueza e a pobreza de uma nação, porém, não são mensuráveis tão-só em termos de PIB e das estatísticas orçamentais. A Universidade de Harvard compreendeu, desde há muito tempo, a importância central do capital humano e 
por isso o seu programa de educação geral recupera, como ficou dito, num contexto de modernidade, o ensino das artes e das ciências liberais da república das letras.

\section{Referências bibiográficas}

BERLIN, Isaiah - El estudio adecuado de la humanidad. Madrid-México: Turner e Fondo de Cultura Económica, 2009.

BOTS, Hans e WAQUET, Françoise - La République des Lettres. Paris: Belin, 1997. BURKE, Peter - Historia social del conocimiento. Barcelona: Paidós, 2002.

ELIAS, Norbert - Scientific Establishments. In ELIAS, Norbert, MARTINS, Herminio e WHITLEY, Richard (eds.) - Scientific Establishments and Hierarchies. Dordrecht: Reidel, 1982.

FUMAROLI, Marc - La République des Lettres. Diogène. Paris: Presses Universitaires de France. N. ${ }^{\circ} 143$ (1988), p. 131-150.

FUMAROLI, Marc - República de las Letras. Barcelona: Alcantilado, 2013.

FumARoli, Marc - Rome et Paris: Capitales de la République européenne des Lettres. Hamburg: LIT Verlag, 1999.

Gomes, Francisco Dias - Obras poeticas. Lisboa: Typographia da Acad. R. das Sciencias, 1799.

GoOdman, Dena - The Republic of Letters. A cultural history of french Enlightenment. Ithaca-London: Cornell University Press, 1994.

LE GOFF, Jacques - Alle origini del lavoro intellettuale in Italia. I problemi del rapporto fra la letteratura, l'università e le professioni. In Letteratura italiana. Volume primo. Il letterato e le istituzioni. Torino: Einaudi, 1982.

QUONDAM, Amedeo (a cura di) - Rinascimento e Classicismo. Materiali per l'analisi del sistema culturale di Antico regime. Roma: Bulzoni Editore, 1999. 
José Augusto Cardoso Bernardes é Professor da Faculdade de Letras da Universidade de Coimbra e Diretor da Biblioteca Geral da Universidade

Ana Maria Eva Miguéis é coordenadora do Serviço Integrado das Bibliotecas da Universidade de Coimbra

Carla Ferreira é bibliotecária nos Serviços de Biblioteca e Documentação da Faculdade de Letras da Universidade de Coimbra. 


\section{Série Documentos}

Imprensa da Universidade de Coimbra

Coimbra University Press

2015

C •

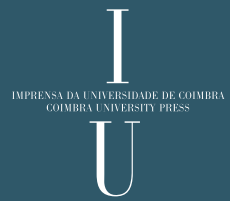

